\title{
A Study for the Nanofinishing of an EN-31 Workpiece with Pulse DC Power Supply Using Ball-End Magnetorheological Finishing
}

\author{
Himmat Singh - M. S. Niranjan* - Reeta Wattal \\ Delhi Technological University, Mechanical Engineering Department, India
}

Ball-end magnetorheological finishing (BEMRF) is a high-level nanofinishing process used in finishing different kinds of surfaces including flat, 2- and 3-dimensional, and curved surfaces. In the present study, a pulse DC power supply is used to energize the electromagnet of magnetorheological (MR) finishing tool. The experiments have been conducted on EN-31 flat workpiece surface with and without pulse DC power supply using a magnetizing current (MC) $2.5 \mathrm{~A}$, a working gap (WG) of $1.5 \mathrm{~mm}$ and a rotational speed of the tool (RST) of $500 \mathrm{rpm}$ with a feed rate of workpiece of $50 \mathrm{~mm} / \mathrm{min}$. The study has been carried out to analyse the effect of the duty cycle on the response percentage reduction in surface roughness. It has been observed that an improved response percentage reduction in surface roughness has been found with pulsating $D C$ power supply as compared to the response percentage reduction in surface roughness obtained with DC power supply without pulse at the same process parameters. After conducting the preliminary experiments, the statistical analysis was done to analyse the effect of various process parameters on the response percentage reduction in surface roughness using response surface methodology (RSM) at 0.16 duty cycle.

Keywords: BEMRF, pulse DC power supply, duty cycle, response percentage reduction in surface roughness

Highlights

- $\quad$ Ball-end magnetorheological finishing (BEMRF) is a high-level nanofinishing process.

- In the present study, the pulse DC power supply is used to energize the electromagnet of magnetorheological (MR) finishing tool.

- It is noted that the better percentage reduction in surface roughness has been achieved with a pulse DC power supply than without pulse DC power supply.

- It is also observed that the surface texture achieved by pulse DC power supply is more even as compared to that obtained without pulse DC power supply.

\section{INTRODUCTION}

In non-traditional finishing processes, the application of magnetic fields has become very important for nano-level finishing on a variety of surfaces. Nano finishing of critical shapes is always difficult to control despite the high demand for nano-finishing. The traditional finishing processes, such as honing, grinding. etc., produce finished surfaces, but these finishing processes produce some thermal and residual stresses on the workpiece surface. It, therefore, becomes a challenge to finish these types of components [1].

Due to advancement in new materials and complex shapes of workpiece geometry, some newly developed advanced finishing processes are employed to resolve such types of problems. One important parameter encountered is surface roughness, which plays a crucial role in high-quality products. These processes are helpful for polishing of any type of materials [2] and [3].

The magnetorheological finishing process, which has more flexibility for process control and a high level of finishing with close dimensional tolerances, can be achieved without leaving any defect on surfaces or subsurfaces. A finishing spot is formed at the tip of finishing tool in magnetorheological finishing, which acts as a semisolid finishing tool that moves over the workpiece surface during finishing of any kind of workpiece surface [4].

Magnetorheological (MR) fluid has more flexibility during the finishing operation; it changes from liquid to semisolid in a very short duration due the effect of the magnetic field. MR fluid is prepared with ferro-magnetic particles and various types of abrasive particles mixed with some base fluid, such as paraffin oil. In advancement of MR fluid for better finishing, bidisperse MR polishing fluid samples have been prepared with different percentages of carbonyl iron powder (CIPs) of standard CS and HS grade (BASF, Germany), and the response has been compared with monodisperse MR polishing fluid. The magnetorheological characterization of bidisperse and monodisperse MR polishing fluid samples have been studied at different magnetic fields with the use of a magnetorheometer [5].

In MR finishing, different process parameters, such as current, working gap, feed rate and central core rotation, have been analysed regarding the response surface roughness. The composition of MR polishing fluid has also been studied; it was observed that the CIPs concentration is the most influential parameter 
on the response surface roughness in comparison to other process parameters for the finishing of hardened AISI 52100 steel [6].

Many finishing techniques based on magnetic fields have been developed. In these techniques, MR fluid behaves like a semisolid finishing spot in the presence of a magnetic field, which is used for finishing action on the workpiece These magnetic finishing techniques include magnetic abrasive finishing (MAF) [7], magnetorheological jet finishing (MRJF) [8], magnetic float polishing (MFP) [9], magnetorheological finishing (MRF) [4], rotational magnetorheological abrasive flow finishing (R-MRAFF) [10], and ball-end magnetorheological finishing (BEMRF) [11]. MAF is a process that has been used to finish flat surfaces, two dimensional (2D) surfaces, and any complex shape of workpiece with high dimensional accuracy. A better-quality product is achieved by the MAF process with a high level of surface finish without any defect on the surface or sub-surface [12].

In the MAF process, direct current (DC) power supply has been used to energize the electromagnet of finishing. Due to the higher demand for the improvement in surface roughness, the MAF process has been used with Pulse DC power supply instead of DC power supply without pulse. Experiments have been conducted with the use of DC power supply and pulsating DC power supply, which showed that there is better surface finish with DC power supply compared to DC power supply without pulse using the same process parameters. It is also observed during continuous DC power supply that the abrasive particles are not so effective for finishing the workpiece surface after a certain time because the cutting edge of abrasive particles loses its finishing capability in finishing zone. While using pulsating DC power supply, the orientation of abrasive particles may be changed or new effective grains of abrasive come in contact with the workpiece surface during finishing, which promotes better surface finish [13].

Many existing magnetic finishing processes have been discussed in the literature, which are not suitable for finishing three dimensional (3D) complexly shaped workpieces, such as narrows cut in workpiece. For the advancement of the MR finishing process with some modification, a BEMRF process has been developed for finishing of any kind of workpiece surface (flat, curved surface, 2D, 3D and stepped surfaces, etc.). The electromagnetic coil of a finishing tool is energized, and MR fluid is used at tip of the tool formed a semisolid ball. The semisolid ball-shaped MR fluid is responsible for the finishing action on the workpiece surface irrespective of any kind of workpiece materials. The BEMRF process can finish any kind of workpiece surface as achieved by finishing in computer navigated controlled (CNC) milling machine for three-dimensional surfaces [14]. This process has major applications in the optics industry, aerospace, and automotive component, among others.

In the present study, an attempt has been undertaken to energize the electromagnetic coil of the BEMRF tool with the help of pulse DC power supply for finishing of a flat EN-31 workpiece which may give improved surface roughness and may increase the efficiency of finishing action of BEMRF process.

\section{METHODS}

Various components of the BEMRF setup are shown in Fig. 1. The setup consists of an electromagnetic coil which is energized as soon as the DC supply is switched $\mathrm{ON}$, which results in the formation of a semisolid hemisphere or ball-shaped finishing spot at the extremity end of the tool as shown in Fig. 1b.
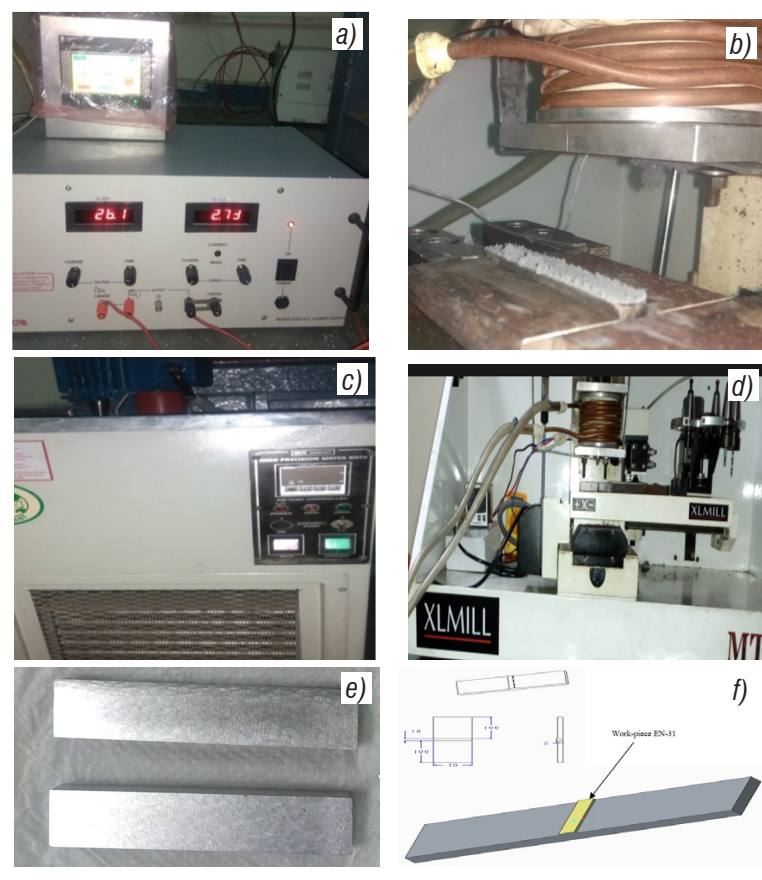

Fig. 1. a) Pulse DC power supply, b) BEMRF tool with MR fluid on workpiece, c) chiller for cooling the electromagnetic coil, d) BEMRF setup, e) EN-31 finished workpiece, f) schematic of die with workpiece dimension in $\mathrm{mm}$

This semisolid ball of MR fluid formed at the tip of tool approximately $15 \mathrm{~mm}$ diameter is used for finishing of EN-31 workpiece. A chiller (Fig. 1c) is 
installed to control the constantly rising temperature of the electromagnetic coil due to the continuous supply of current.

\subsection{Mechanism of Material Removal}

In the BEMRF process, the DC power supply is used to energize the electromagnetic coil due to which a semisolid hemisphere or ball-shaped finishing spot of MR polishing fluid is established at the extremity end of the tooltip. The semisolid finishing spot is used for finishing of surfaces such as flat, curved surface, 2D, $3 \mathrm{D}$, and stepped surfaces irrespective of the movement of finishing tool. The semisolid ball-shaped finishing spot has more pliability to move over any kind of workpiece surface for finishing. In conventional MR finishing process, the abrasive particles in contact with the workpiece do not change their orientation in the entire finishing time due to fixed magnetic flux density. As a result, the cutting edges of the abrasive particles become dull, resulting in poor surface finish. In order to further enhance the finishing efficiency, the fresh active abrasive particles are required again and again to finish the workpiece surface, which is not possible with conventional MR finishing process. To overcome this limitation, an improvement has been made in the conventional MR finishing process by providing fluctuating DC power supply.

a)

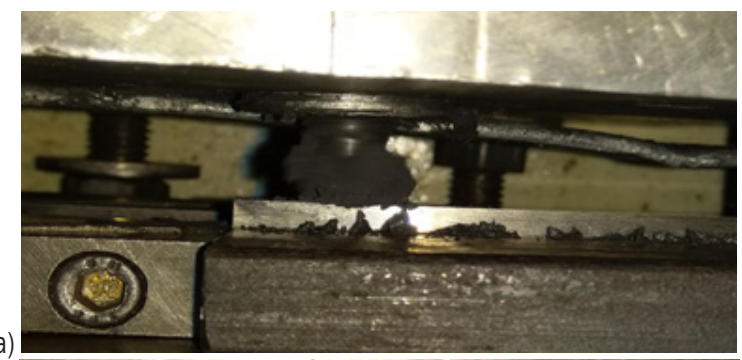

b)

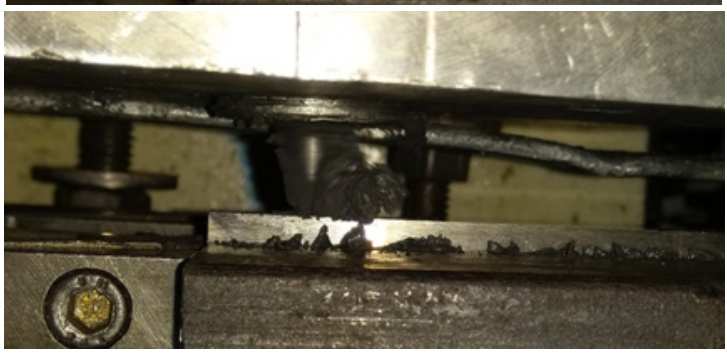

Fig. 2. Mechanism of material removal in BEMRF process; a) ball is formed at finishing tool with pulse DC power supply (TON condition), b) ball is formed at finishing tool with pulse DC power supply (TOFF condition)

Pulse DC power supply is given to the BEMRF finishing tool, which produces a fluctuating magnetic field on the tip of MR finishing tool. Therefore, fresh active abrasive grains may come outward or the orientation of abrasive particles may be changed and the finishing action of abrasive particles over the surface of workpiece in direct contact enhances the finishing efficiency of BEMRF process. During the process, the viscosity of MR polishing fluid reduces as soon as the DC power supply is switched off for very short duration, which results in changing the semisolid ball towards liquid a state. As soon as the power supply is $\mathrm{ON}$, the orientation of the abrasive particles is changed due to the fluctuating magnetic field or some new active abrasive grains may move outward. as shown in Fig. 2a. As soon as the power supply is OFF, the orientation of the abrasive particles is changed due to the fluctuating magnetic field, as shown in Fig. 2b. The frequent ON and OFF of DC power supply results in orientation change of abrasive particles, hence fresh abrasive particles come in contact with the workpiece surface.

\section{EXPERIMENTAL}

The experimental setup has an electromagnetic coil, pulse DC power supply, thermocouple, and a chiller for cooling the electromagnetic coil is shown in Fig. 1. A semisolid hemisphere ball of MR polishing fluid and pulsed BEMRF setup is given in Fig. $1 \mathrm{~b}$ and $\mathrm{d}$, respectively. MR polishing fluid changes from liquid to semisolid state and behaves like a semisolid hemispherical ball due to the magnetic flux density produced by the electromagnetic coil.

A homogenous mixture of MR polishing fluid was synthesized with silicon carbide abrasive particles of 800 mesh size (25 vol\%) with density $d 3.33 \mathrm{gm} /$ $\mathrm{cm}^{3}$, ferro magnetic iron particles (CIP CS grade, 20 vol\%) with density $d 7.8 \mathrm{gm} / \mathrm{cm}^{3}$ and $55 \mathrm{vol} \%$ of base fluid. When a magnetic field is present at the tip of the tool, ferro-magnetic iron particles (CIPs) engaged to each other form a chain-like columnar structure in which abrasive particles are positioned between magnetic particles (CIPs). A semisolid MR polishing fluid ball is formed at the tip of tool, which moves over the workpiece surface and hence material is sheared off the workpiece surface in the form of very small chips.

The workpiece position and its die are given in Fig. 1f. The total height of the workpiece is $10 \mathrm{~mm}$, the depth of the slot is $8 \mathrm{~mm}$ and, during the finishing operation, the workpiece is kept slightly above 2 $\mathrm{mm}$ from slot depth. The preparatory experiments were conducted to attain the intended purpose of the 
finishing process and to develop the ranges of the duty cycle parameters.

Duty cycle $r$ is given as:

$$
r=T_{O N} /\left(T_{O N}+T_{O F F}\right)
$$

Here $T_{O N}$ and $T_{O F F}$ denotes on-time \& off-time of pulse DC power supply respectively. The preliminary experiments have been carried out on an EN-31 flat workpiece surface with and without pulse DC power supply given to electromagnetic coil. The approximate values for parameters are selected on the basis of the literature review done in this work [15] to [17]. These values contributed to the notable results observed in the studies highlighted by the above references. These experiments have been conducted using process parameters made up of; working gap $1.5 \mathrm{~mm}$, tool rotational speed $500 \mathrm{rpm}$, current $2.5 \mathrm{~A}$, and finishing time of $30 \mathrm{~min}$. These parameters were employed with DC power supply at different duty cycles with and without pulses. The response parameter percentage reduction in surface roughness $(\% \Delta R a)$ was calculated using;

$$
\% \Delta R_{a}=\frac{\text { initial roughness }- \text { final roughness }}{\text { initial roughness }} \times 100 \% \text {. }
$$

A Talyor Hobson surface analyser was used with cut-off length $0.8 \mathrm{~mm}$ and data length of $4 \mathrm{~mm}$ to measure surface roughness.

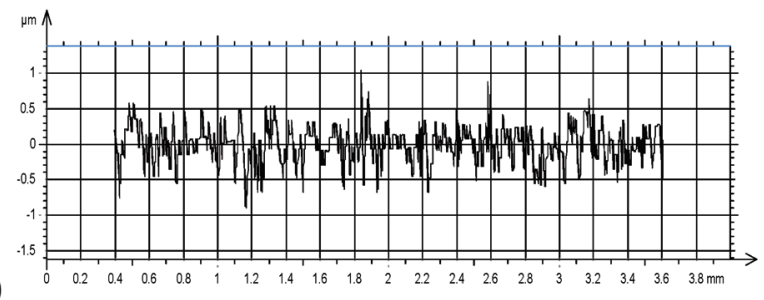

\section{RESULT AND DISCUSSION}

The roughness profile of EN-31 workpiece surface with DC power supply without pulse is shown in Fig. 3 . The percentage reduction in surface roughness was calculated and given in Table 1 and 2.

The roughness profile of the finished EN31 workpiece surface was drawn after conducting experiments with pulse DC power supply at 0.16 duty cycles, as shown in Fig. $4 \mathrm{~b}$ and $\% \Delta R a$ has been calculated, which is given in Table 1. It is observed that the $\% \Delta R a$ has been found better by conducting the experiments with pulse DC power supply at 0.16 duty cycle as compared to $\% \Delta R a$ obtained by DC power supply without pulse.

The surface roughness profile of finished EN-31 workpiece surface has been drawn after conducting experiments with pulse DC power supply at 0.27 duty cycle is shown in Fig. 5b.

The percentage reduction in surface roughness was calculated for preliminary experiments at various duty cycles and given in Table 1 . A total of eighteen experiments were performed with three repletion for each sample (total number of samples $=6$ ). It has been observed from the experimental study that the best $\% \Delta R a$ was found at 0.16 duty cycle.

It is observed from Fig. 6 that the highest $\% \Delta R a$ is found to be $37.09 \%$ at 0.16 duty cycle and is lowest

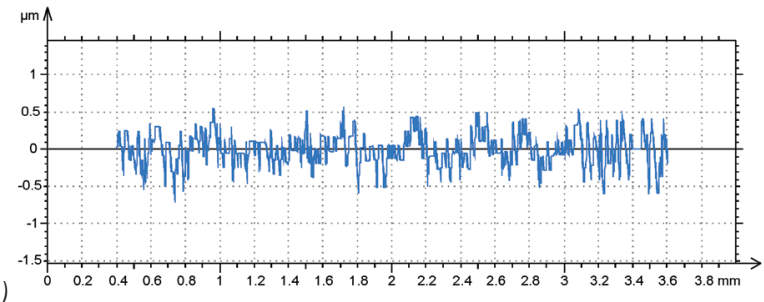

Fig. 3. a) Surface roughness profile of EN-31 before finishing, $(R a=0.187 \mu \mathrm{m}, R q=0.244 \mu \mathrm{m}, R z=1.56 \mu \mathrm{m})$; b) surface roughness profile after finishing using $D C$ power supply without pulse $(R a=0.161 \mu \mathrm{m}, R q=0.203 \mu \mathrm{m}, R z=1.13 \mu \mathrm{m})$

\begin{tabular}{|c|c|c|c|c|c|c|c|}
\hline Exp. no. & Duty cycle & on-time [ms] & off-time [ms] & Pulse time & Initial $R a[\mu \mathrm{m}]$ & Final $R a[\mu \mathrm{m}]$ & $\% \Delta R a$ \\
\hline 1 & 0.45 & 4 & 5 & 9 & 0.197 & 0.172 & 12.69 \\
\hline 2 & 0.36 & 4 & 7 & 11 & 0.194 & 0.161 & 17.01 \\
\hline 3 & 0.16 & 4 & 21 & 25 & 0.186 & 0.117 & 37.09 \\
\hline 4 & 0.27 & 4 & 11 & 15 & 0.197 & 0.149 & 24.36 \\
\hline 5 & 0.61 & 4 & 3 & 7 & 0.197 & 0.185 & 6.09 \\
\hline 6 & 0.67 & 4 & 2 & 6 & 0.185 & 0.176 & 4.86 \\
\hline
\end{tabular}

Table 1. Preliminary experimentation details with pulse supply

Table 2. Preliminary Experimentation without pulse supply

\begin{tabular}{cccccccc}
\hline Exp no. & MC $[\mathrm{A}]$ & RST $[\mathrm{rpm}]$ & WG $[\mathrm{mm}]$ & Time $[\mathrm{min}]$ & Initial $R a[\mu \mathrm{m}]$ & Final $R a[\mu \mathrm{m}]$ & $\% \Delta R a$ \\
\hline 1 & 2.5 & 500 & 1.5 & 30 & 0.187 & 0.161 & 13.44 \\
\hline
\end{tabular}



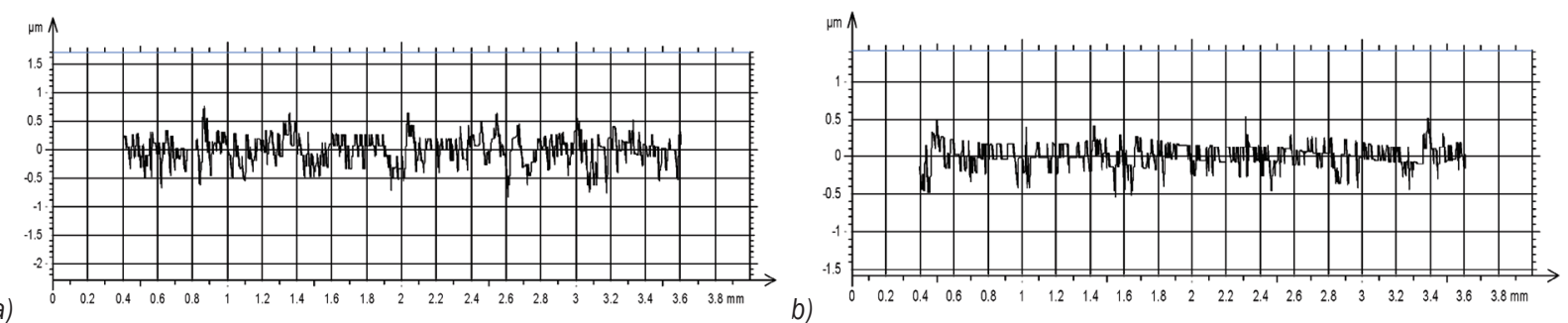

Fig. 4. a) Roughness profile before finishing of EN-31 workpiece surface ( $R a=0.187 \mu \mathrm{m}, R q=0.235 \mu \mathrm{m}, R z=1.42 \mu \mathrm{m})$;

b) Surface roughness profile after finishing with pulse $D C$ power supply at 0.16 duty cycle $(R a=0.117 \mu \mathrm{m}, R q=0.151 \mu \mathrm{m}, R z=0.95 \mu \mathrm{m})$;
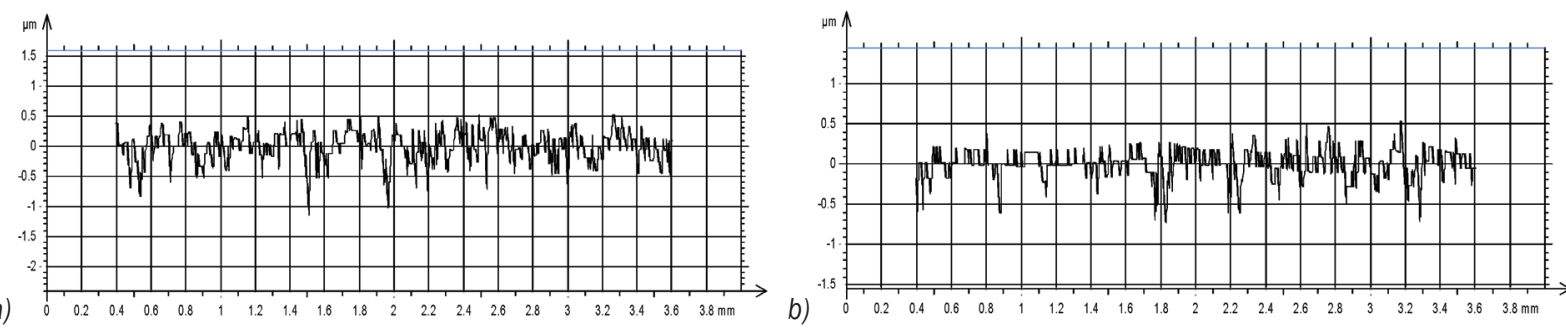

Fig. 5. a) Roughness profile before finishing of EN-31 workpiece surface $(R a=0.197 \mu \mathrm{m}, R q=0.255 \mu \mathrm{m}, R z=1.4 \mu \mathrm{m})$;

b) surface roughness profile after finishing with pulse DC power supply at 0.27 duty cycle $(R a=0.149 \mu \mathrm{m}, R q=0.198 \mu \mathrm{m}, R z=1.16 \mu \mathrm{m})$

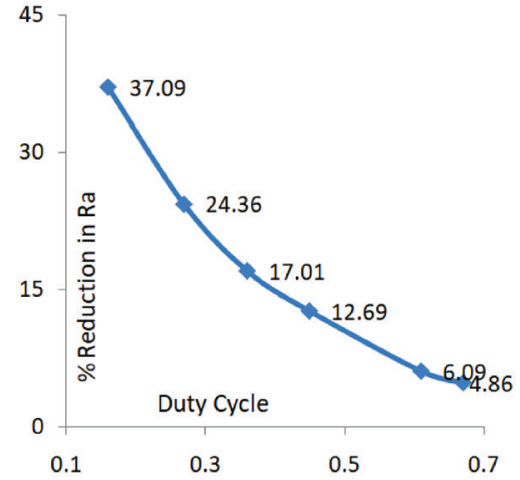

Fig. 6. Relationship between percentage reductions in surface roughness with the duty cycle

at 0.67 duty cycle. The $\% \Delta R a$ is found to be $13.44 \%$ on conducting the experiments with DC power supply without pulse. It is due to the adopted technique that the fresh active abrasive grains change their orientation and come in contact with workpiece surface directly during finishing action, which enhances the finishing efficiency of BEMRF process. During the process, the viscosity of MR fluid reduces as soon as the DC power supply is switched off for a very short duration. As soon as the power supply is ON, the orientation of the abrasive particles get changed due to the fluctuating magnetic field, or some new active abrasive grains may come outward. The frequent $\mathrm{ON}$ and OFF of DC power supply results in orientation change of abrasive particles; thus, fresh abrasive grains may come in contact with the workpiece surface.

The optical microscopic views of finished EN-31 workpiece surface with and without pulse DC power supply are shown in Fig. 7. The best texture of surface finished using the pulse DC power supply was found at duty cycle 0.16 , as shown in Fig. 7c, as compared
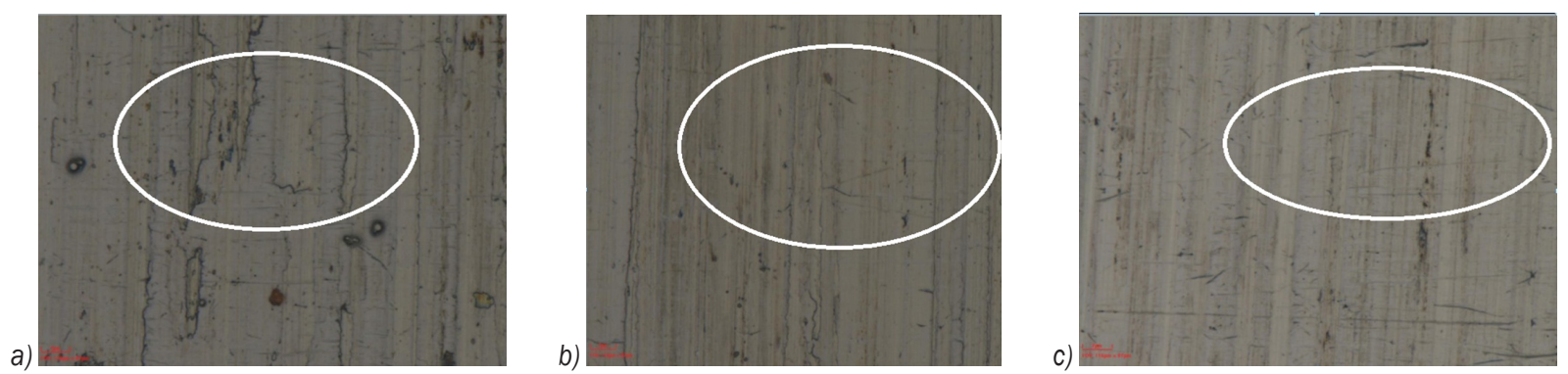

Fig. 7. Optical microscopic views of finished surface; a) with DC power supply without pulse, b) with pulse DC power supply at 0.27 duty cycle, c) with pulse DC power supply at 0.16 duty cycle 
a)
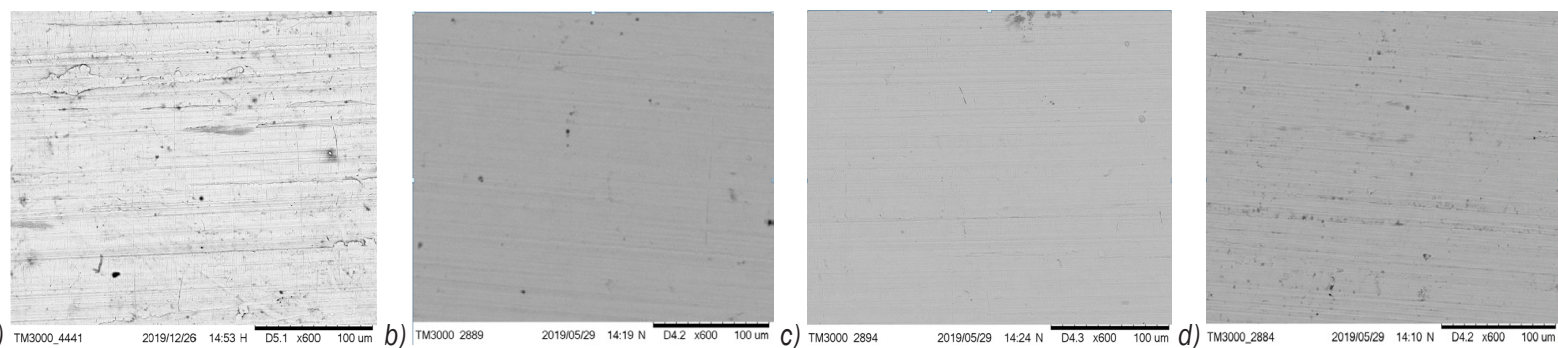

Fig. 8. SEM images of workpiece surface: a) before finish (lays are present on the initial grinded surface), b) finished workpiece surface (Improved surface texture) at 0.27 duty cycle, c) finished workpiece surface (better improved surface texture) at 0.16 duty cycle, d) finished workpiece surface (less improved surface) with DC power supply without pulse

to the surface finished with DC power supply without pulse, as shown in Fig. 7a. From optical microscopic views of the finished surface, it was found that the surface texture is observed improved as the duty cycle decrease from 0.27 to 0.16 .

Scanning electron micrograph (SEM) of the EN31 workpiece surface is shown at $100 \mu \mathrm{m}$ resolution and $600 \times$ magnification as outlined in Fig. 8. The lays are clearly visible in the initial grinded surface, as shown in Fig. 8a. It is observed from Fig. 8c that a more uniform finished surface is obtained with pulse DC power supply at 0.16 duty cycle as compared to the finished surface obtained with DC power supply without pulse, as shown in Fig. 8d. From Fig. 8b and $\mathrm{c}$, it is shown that as the duty cycle decreases from 0.27 to 0.16 , and a better surface texture is achieved at 0.16 duty cycle.

\section{DESIGN OF EXPERIMENT}

The present work utilizes central composite design (CCD) under response surface methodology to design the experiments based on the preliminary study. In this regression analysis, three parameters are used $(W G$, $M C$ and $R S T$ ) to determine the significance of these parameters on output responses $\% \Delta R a$. The most appropriate value of duty cycle was found to be 0.16 , for which the highest $\% \Delta R a$ observed. Therefore, the 0.16 duty cycle was taken for all experiments. The run order and results of output responses for the finishing of EN-31 using BEMRF process are shown in Table 3.

\section{RESULTS}

\subsection{Analysis of Surface Roughness}

Insignificant terms having $p$-value greater than 0.05 are eliminated by using backward elimination, and the pooled ANOVA results for surface roughness are presented in Table 4 . Table 3 shows the $\% \Delta R a$ for the EN-31 workpiece before and after finishing through the BEMRF process.

Table 3. Design and result of output response in surface roughness $(\% \Delta R a)$

\begin{tabular}{cccccc}
\hline $\begin{array}{c}\text { Std } \\
\text { order }\end{array}$ & $\begin{array}{c}\text { Run } \\
\text { order }\end{array}$ & $\begin{array}{c}M C \\
{[\mathrm{~A}]}\end{array}$ & $\begin{array}{c}R S T \\
{[\mathrm{rpm}]}\end{array}$ & $\begin{array}{c}W G \\
{[\mathrm{~mm}]}\end{array}$ & $\% \Delta R a$ \\
\hline 16 & 1 & 2.5 & 700 & 1.5 & 34.49 \\
\hline 12 & 2 & 3 & 400 & 1 & 39.17 \\
\hline 4 & 3 & 2.5 & 300 & 1.5 & 28.25 \\
\hline 1 & 4 & 3.5 & 500 & 1.5 & 40.69 \\
\hline 10 & 5 & 2 & 400 & 1 & 26.6 \\
\hline 14 & 6 & 3 & 600 & 2 & 31.12 \\
\hline 15 & 7 & 3 & 400 & 2 & 29.12 \\
\hline 13 & 8 & 2.5 & 500 & 1.5 & 33.48 \\
\hline 17 & 9 & 2 & 400 & 2 & 24.38 \\
\hline 20 & 10 & 2.5 & 500 & 2.5 & 23.22 \\
\hline 6 & 11 & 1.5 & 500 & 1.5 & 20.68 \\
\hline 7 & 12 & 2 & 600 & 2 & 26.99 \\
\hline 11 & 13 & 2.5 & 500 & 1.5 & 32.06 \\
\hline 5 & 14 & 2 & 600 & 1 & 27.9 \\
\hline 9 & 15 & 2.5 & 500 & 0.5 & 37.03 \\
\hline 2 & 16 & 2.5 & 500 & 1.5 & 32.48 \\
\hline 3 & 17 & 3 & 600 & 1 & 40.37 \\
\hline 19 & 18 & 2.5 & 500 & 1.5 & 32.48 \\
\hline 18 & 19 & 2.5 & 500 & 1.5 & 32.1 \\
\hline 8 & 20 & 2.5 & 500 & 1.5 & 32.23 \\
\hline & & & & & \\
\hline
\end{tabular}

In the tool Design-Expert, the quadratic model is selected on the basis of the lack of fit tests, since the cubic model is aliased. Table 4 shows the significant terms after analysis of variance (ANOVA). The $p$-value less than 0.05 shows that the model parameters are significant. In this reduced model of ANOVA, the following terms $\mathrm{A}, \mathrm{B}, \mathrm{C}, \mathrm{AC}, \mathrm{A}^{2}$ and $\mathrm{C}^{2}$ are found to be significant as shown in Table 4. $f$-value is 108.61, which indicates that the model is significant. There is only $0.01 \%$ possibility of this to occur due to noise. 
Table 4. ANOVA for $\% \Delta R a$

\begin{tabular}{lccccc}
\hline Source & $\begin{array}{c}\text { Sum of } \\
\text { Squares }\end{array}$ & DOF & MSE & $f$-value & $p$-value \\
\hline Model & 565.92 & 6 & 94.32 & 108.61 & $<0.0001$ sign \\
\hline $\mathrm{A}-M C$ & 341.6 & 1 & 341.6 & 393.36 & $<0.0001$ \\
\hline $\mathrm{B}-R S T$ & 23.99 & 1 & 23.99 & 27.62 & 0.0002 \\
\hline $\mathrm{C}-W G$ & 156.56 & 1 & 156.5 & 180.28 & $<0.0001$ \\
\hline $\mathrm{AC}$ & 32.68 & 1 & 32.68 & 37.64 & 0.0376 \\
\hline $\mathrm{A} 2$ & 4.65 & 1 & 4.65 & 5.36 & 0.0087 \\
\hline $\mathrm{C} 2$ & 8.27 & 1 & 8.27 & 9.53 & \\
\hline Residual & 11.29 & 13 & 0.868 & & \\
\hline Lack of fit & 9.91 & 8 & 1.24 & 4.48 & 0.0577 not sig \\
\hline Pure error & 1.38 & 5 & 0.2766 & & \\
\hline Cor Total & 577.21 & 19 & & & \\
\hline
\end{tabular}

The equation for $\% \Delta R a$ in term of actual factor as is given below:

$$
\begin{aligned}
\% \Delta R a & =-33.6820+29.77 \times \mathrm{A}+0.0122 \times \mathrm{B} \\
& +20.679 \times \mathrm{C}-8.08 \times \mathrm{A} \times \mathrm{C}-1.68 \times \mathrm{A}^{2}-2.24 \times \mathrm{C}^{2}
\end{aligned}
$$

\section{DISCUSSION}

The results obtained after finishing of EN-31 using BEMRF process and the effect of parameters on $\% \Delta R a$ are discussed in this section.

\subsection{Effect of Rotational Speed of Tool (RST)}

Fig. 9 outlines the effect of RST on $\% \Delta R a$ at various $W G$ and at constant $M C 2.5 \mathrm{~A} \& 0.16$ duty cycle. The $\% \triangle R a$ slightly increasing with the increase in $R S T$ at all $W G$. The effect of $R S T$ reveals that it is the least contributing parameter on $\% \Delta R a$ with a $4.17 \%$ (from model analysis).

\subsection{Effect of Magnetizing Current (MC)}

Fig. 10 describes the effect of $M C$ on $\% \Delta R a$ at various $R S T$ and at a constant 0.16 duty cycle \& working gap $1.5 \mathrm{~mm}$. The $\% \Delta R a$ increased with the increasing in $M C$ at all $R S T$. The $M C$ is the highest contributing parameter on $\% \Delta R a$ with $59.18 \%$ (from model analysis). It is also seen from the perturbation or $3 \mathrm{D}$ surface diagram, as shown in Fig. 12a and b. As the magnetic flux increases, the magnetic force acting on $\mathrm{SiC}$ abrasive particle increases due to which high $\% \Delta R a$ is achieved at 0.16 duty cycle.

\subsection{Effect of Working Gap (WG)}

Fig. 11. explains the effect of $W G$ on $\% \Delta R a$ at various $M C$ and at constant 0.16 duty cycle \& RST $500 \mathrm{rpm}$.

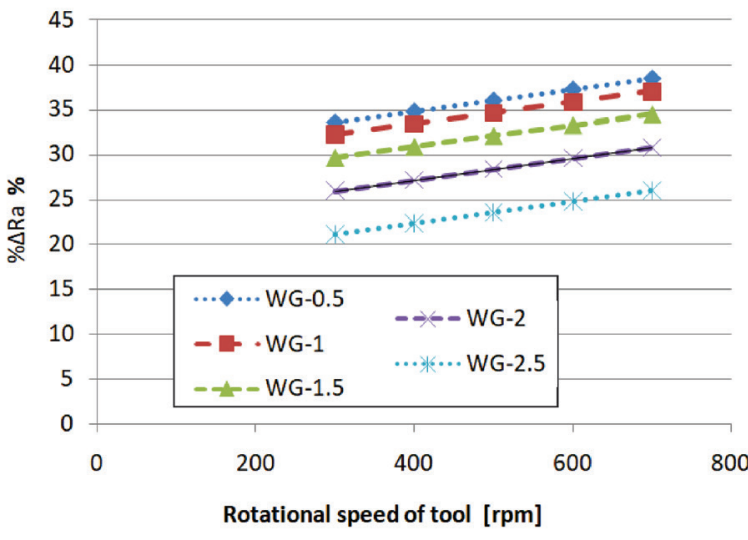

Fig. 9. Effect of RST on $\% \Delta R a$ at $2.5 \mathrm{~A}$

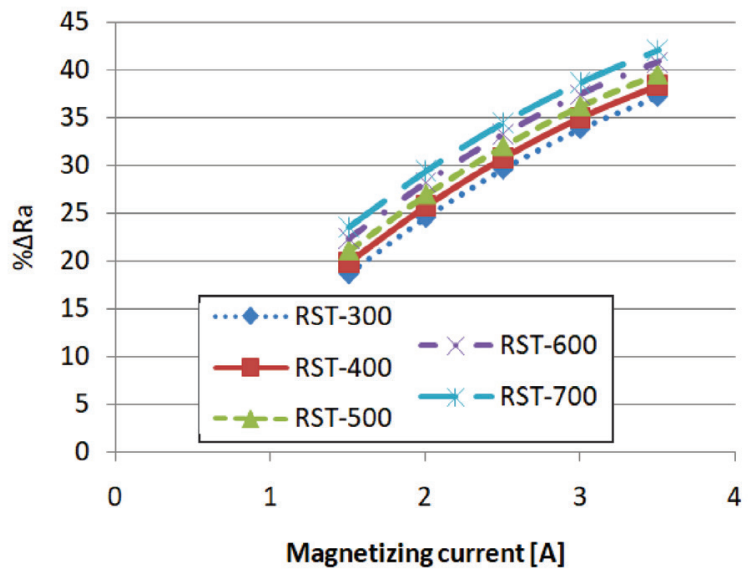

Fig. 10. Effect of $M C$ on $\% \Delta R$ a at $W G 1.5 \mathrm{~mm}$

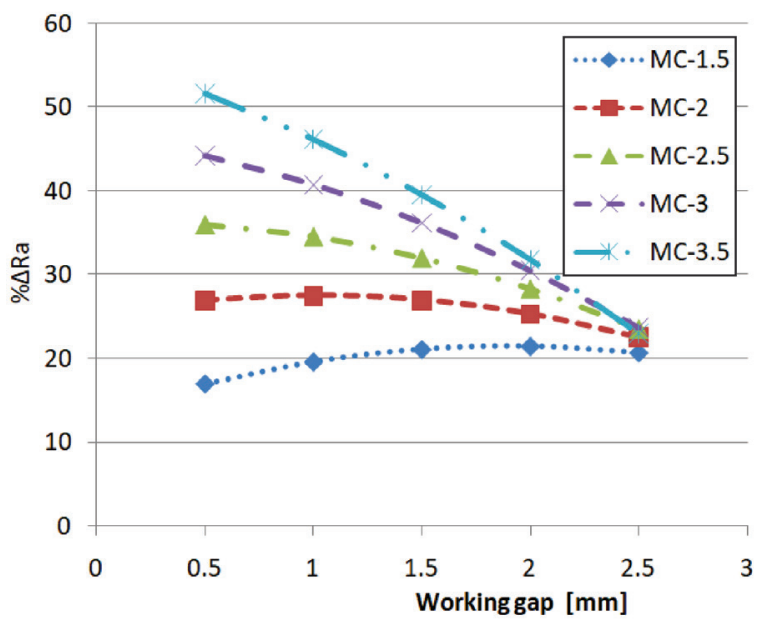

Fig. 11. Effect of $W G$ on $\% \Delta R a$ at $500 \mathrm{rpm}$

The $\% \Delta R a$ decreases with the increase in $W G$ at all $M C$. The effect of $W G$ reveals that it is second most contributing parameter on $\% \Delta R a$ with $27.12 \%$ (from model analysis). It is also seen from the perturbation or 3D surface diagram, as shown in Fig. 12a and c. 


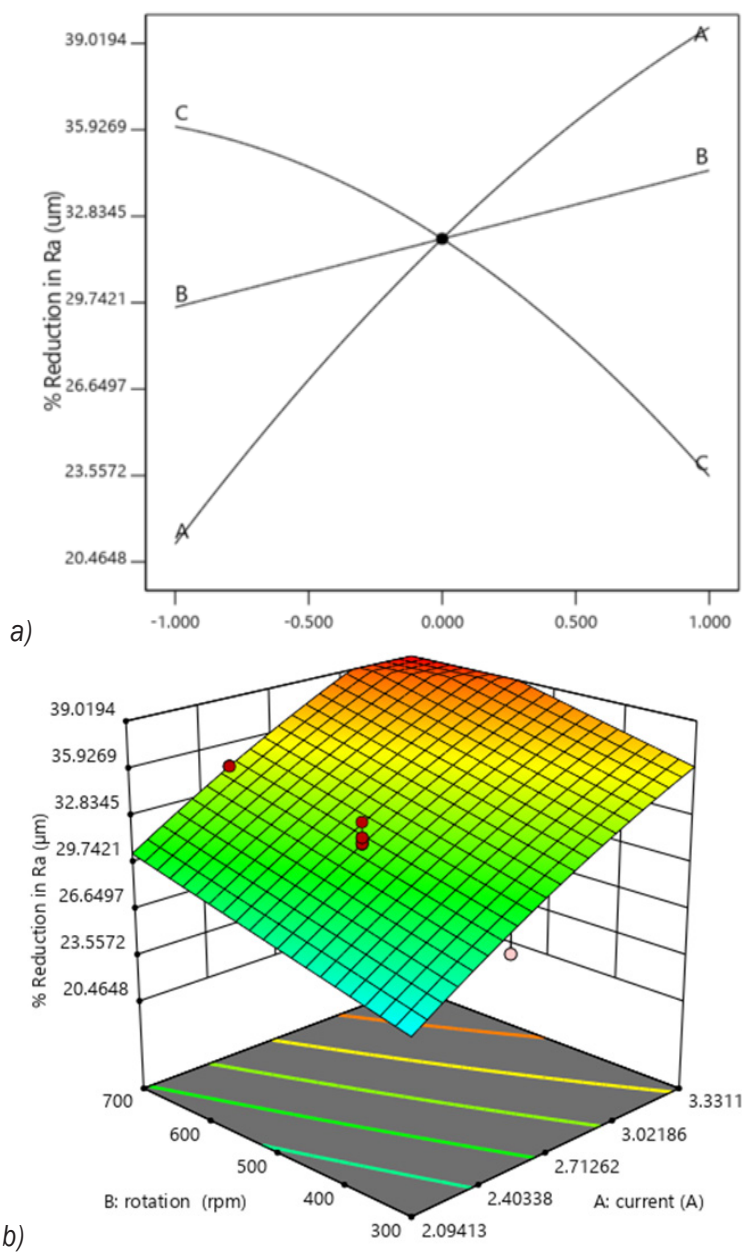

b)

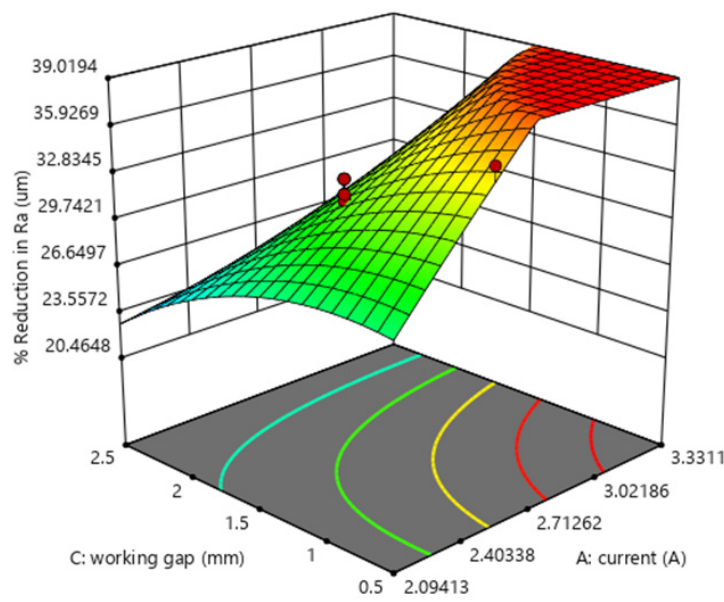

Fig. 12. a) Perturbation diagram for $\% \Delta R a$ ( $A$ - current, $B$ - working gap, C- current), b) and c) 3D surface for $\% \Delta R a$

\section{CONCLUSIONS}

The following conclusions are drawn on the study with ball-end magnetorheological finishing process with and without pulse DC power supply.
1. It is noted that the best percentage reduction in surface roughness $(\% \Delta R a)$ was achieved with pulse DC power supply than without pulse DC power supply.

2. The $\% \Delta R a$ is found as $37.09 \%$ at 0.16 duty cycle and $24.36 \%$ at 0.27 duty cycle while $13.44 \%$ with DC power supply without pulse.

3. It was also observed that the surface texture achieved by pulse DC power supply is more monotonous as compared to without pulse DC power supply.

4. The effect of different rotational speeds of the tool, $R S T$ is found to be the least contributing parameter on $\% \Delta R a$ with a reduction of $4.17 \%$ at 0.16 duty cycle.

5. The $\% \Delta R a$ increased with the increase in magnetizing current, $M C$ at all $R S T$. It is the highest contributing parameter on $\% \Delta R a$ with a reduction of $59.18 \%$ at 0.16 duty cycle.

6. The $\% \Delta R a$ decreases with the increasing in $W G$ at all $M C$. It is second most contributing parameter on $\% \Delta R a$ with a reduction of $27.12 \%$.

\section{ACKNOWLEDGEMENTS}

I would like to show our gratitude to the Delhi technological university for providing experimental setup and for sharing their pearls of wisdom with me during the course of this research.

\section{NOMENCLATURES}

$d \quad$ density, $\left[\mathrm{g} / \mathrm{cm}^{3}\right]$

$M C$ magnetizing current, [A]

$W G \quad$ working gap, [mm]

$R a$ surface roughness, $[\mu \mathrm{m}]$

$R S T$ rotational speed of tool, [rpm]

$\% \triangle R a$ response parameter percentage reduction in surface roughness, [\%]

$r \quad$ duty cycle, [-]

$T_{O N} \quad$ on-time of pulse DC power [ms]

$T_{\text {OFF }} \quad$ off-time of pulse DC power [ms]

\section{REFERENCES}

[1] Kordonski, W., Golini, D. (1998). Magnetorheological suspension-based high precision finishing technology (MRF). Journal of Intelligent Material Systems and Structures, vol. 9, no. 8, p. 650-654, Dol:10.1177/1045389x9800900811.

[2] Jain, V.K., Jayswal, S.C., Dixit, P.M. (2007). Modeling and simulation of surface roughness in magnetic abrasive finishing using non-uniform surface profiles. Journal of Materials and Manufacturing Processes, vol. 22, no. 2, p. 256-270, Dol:10.1080/10426910601134096. 
[3] Zhong, Z.W. (2008). Recent advances in polishing of advanced materials. Journal of Materials and Manufacturing Processes, vol. 23, no. 5, p. 449-456, DOI:10.1080/10426910802103486.

[4] Kordonski, W.I., Jacobs, S.D. (1996). Magnetorheological finishing. International Journal of Modern Physics B, vol. 10, no. 23-24, p. 2837-2848, D0l:10.1142/S0217979296001288.

[5] Niranjan, M.S., Jha, S. (2014). Flow behaviour of bidisperse MR polishing fluid and ball end MR finishing. Procedia Materials Science, vol. 6, p. 798-804, D0l:10.1016/j. mspro.2014.07.096.

[6] Maan, S., Singh, A.K. (2018). Nano-surface finishing of hardened AISI 52100 steel using magnetorheological solid core rotating tool. The International Journal of Advanced Manufacturing Technology, vol. 95, p. 513-526, D0l:10.1007/ s00170-017-1209-x.

[7] Shinmura, T., Takazawa, K., Hatano, E., Aizawa, T. (1985). Study on magnetic abrasive process-process principles and finishing possibility. Japan Society of Precision Engineering, vol. 19, no. 1, p. 54-55.

[8] Kordonski, W.I., Shorey, A.B., Tricard, M. (2006). Magnetorheological jet finishing technology. Journal of Fluids Engineering, vol. 128, no. 1, p. 20-26, DOl:10.1115/1.2140802.

[9] Komanduri, R. (1996). On material removal mechanisms in finishing of advanced ceramics and glasses. CIRP Annals, vol. 45, no. 1, p. 509-514, D0l:10.1016/S0007-8506(07)63113-8.

[10] Das, M., Jain, V.K. Ghoshdastidar, P.S. (2012). Nanofinishing of flat workpieces using rotational-magnetorheological abrasive flow finishing (R-MRAFF) process. The International Journal of Advanced Manufacturing Technology, vol. 62, p. 405-420, D0I:10.1007/s00170-011-3808-2.
[11] Singh, A.K., Jha, S., Pandey, P. (2012). Magnetorheological ball end finishing process. Materials and Manufacturing Processes, vol. 27, no. 4, p. 389-394, D0l:10.1080/1042691 4.2011.551911.

[12] Shinmura, T., Takajava, K., Hatano, E. (1985). Study on magnetic abrasive process - Application to plane finishing. Bulletin of the Japan Society of Precision Engineering, vol. 19, no. 4, p. 289-291.

[13] Jain, V.K., Singh, D.K., Raghuram, V. (2008). Analysis of performance of pulsating flexible magnetic abrasive brush (P-FMAB). Machining Science and Technology, vol. 12, no. 1, p. 53-76, DOI:10.1080/10910340701883538.

[14] Singh, A.K., Jha, S., Pandey, P.M. (2011). Design and development of nanofinishing process for 3D surfaces using ball end MR finishing tool. International Journal of Machine Tools \& Manufacture, vol. 51, no. 2, p. 142-151, DOI:10.1016/j.jjmachtools.2010.10.002.

[15] Singh, A.K., Jha, S., Pandey, P.M. (2015). Performance analysis of ball end magnetorheological finishing process with MR polishing fluid. Materials and Manufacturing Processes, vol. 30, no. 12, p. 1482-1489, Dol:10.1080/10426914.2015 .1019098 .

[16] Sidpara, A., Jain, V.K. (2012). Theoretical analysis of forces in magnetorheological fluid based finishing process. International Journal of Mechanical Sciences, vol. 56, no. 1, p. 50-59, D0I:10.1016/j.ijmecsci.2012.01.001.

[17] Singh, A.K., Jha, S., Pandey, P.M. (2013). Magnetorheological finishing process, mechanism of material removal in ball end magnetorheological finishing process. Wear, vol. 302, no. 1-2, p. 1180-1191, D0I:10.1016/j.wear.2012.11.082. 